\title{
corrections
}

\section{A CTG trinucleotide repeat expansion in the gene encoding junctophilin-3 is associated with Huntington disease-like 2}

S E Holmes, E O'Hearn, A Rosenblatt, C Callahan, H S Hwang, R G Ingersoll-Ashworth, A Fleisher, G Stevanin, A Brice, N T Potter, C A Ross \& R L Margolis

Nature Genet. 29, 377-378 (2001).

In the first sentence of the final paragraph, the locus $16 \mathrm{q} 23.4$ is incorrect. The corrected sentence is "Our results suggest that CAG/CTG repeat expansions of about 40 or more triplets at the HDL2 locus on 16q24.3 cause HDL2."

In Fig. $2 e$, the cDNA that is labeled ' $(\mathrm{CTG})_{n}=$ polyalanine' should be labeled: '(CTG $)_{n}=$ polyleucine'. The second to last sentence of the legend to Fig. 2 is missing a comma; the sentence should be: "Depending on the splice acceptor site, the repeat is in a 3 ' untranslated region, in the frame to encode polyalanine, or in the frame to encode polyleucine."

errata

MID1, mutated in Opitz syndrome, encodes a ubiquitin ligase that targets phosphatase 2A for degradation

A Trockenbacher, V Suckow, J Foerster, J Winter, S Kraus, H-H Ropers, R Schneider \& S Schweiger

Nature Genet. 29, 287-294 (2001).

The correct date of receipt is 8 January 2001.

\section{A QTL for flowering time in Arabidopsis reveals a novel allele of CRY2}

S El-Assal, C Alonso-Blanco, A J M Peeters, V Raz \& M Koornneef

Nature Genet. 29, 435-440 (2001).

By error, three corrections were not made to proofs of the manuscript during its preparation for the press.

The last sentence in the legend of Fig. 1 and the penultimate sentence of the sixth paragraph refer to (an) "untranscribed" region(s). They should refer, instead, to (an) "untranslated" region(s).

An asterisk, indicating a control protein to which anti-CRY2 antibody non-specifically binds, should have appeared in Fig. $4 c$. The corrected panel follows.

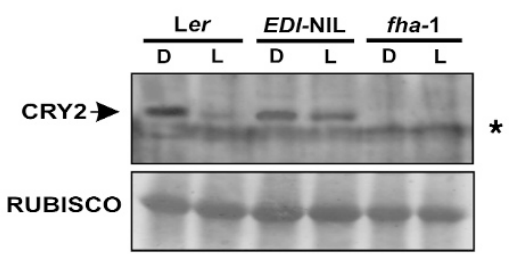

\section{Mutations in PTPN11, encoding the protein tyrosine phosphatase SHP-2, cause Noonan syndrome}

M Tartaglia, E L Mehler, R. Goldberg, G Zampino, H G Brunner, H Kremer, I van der Burgt, A H Crosby, A lon, S Jeffery, K Kalidas, M A Patton, R S Kucherlapati \& B D Gelb

Nature Genet. 29, 465-468 (2001).

The locus for Noonan syndrome was incorrectly referred to as N-SH2, in the introductory paragraph. The third sentence of the paragraph should read: "It has been mapped to a 5-cM region (NS1) on chromosome 12q24.1, and genetic heterogeneity has also been documented ${ }^{3-6}$." 